Psychother Psychosom 2012;81:391-393

DOI: $\underline{10.1159 / 000341183}$

\section{Towards Implementing the Biopsychosocial Factor in National Health Care Systems: The Role of Postgraduate Training in Austria}

\author{
Christian Fazekas ${ }^{\mathrm{a}}$, Anton Leitner ${ }^{\mathrm{b}}$ \\ a Department of Medical Psychology and Psychotherapy, \\ Medical University of Graz, Graz, and bepartment for \\ Psychotherapy and Biopsychosocial Health, Faculty of Health \\ and Medicine, Danube University Krems, Krems, Austria
}

In this year's opening editorial, Fava et al. [1] introduced the 'biopsychosocial factor'. They referred to George Engel's publication [2] in Science on the need for a new medical model and pointed to the 'dangerous' parts of this paper. These parts deal with Engel's remarks on the significance of commercial interests in medicine, the impact of a decline of clinical observation, and the clinical inadequacy of the concept of disease. In this context, in accordance with Tinetti and Fried [3], Fava et al. argued that clinical decision-making for all patients should be addressed to the attainment of individual goals and the identification and treatment of all modifiable factors, including non-biological ones, rather than solely on the diagnosis and treatment of individual diseases. In order to provide a stimulus for a psychosomatic renewal of health care, the authors proposed the 'biopsychosocial factor' as a more dynamic concept than a 'model' implies. In addition, they pointed to novel assessment methods that could help improve the clinical process. In this contribution we aim to underline and amplify the suggestion of the biopsychosocial factor by relating it to the Austrian national health care system approach to psychosomatic medicine. This approach has developed a strong focus on postgraduate training which is open to several medical specialties. It is intended to lead to a more structured implementation of biopsychosocial medicine. It should be mentioned that the Austrian health care system is financed by public money. Additional health care services are provided by the private sector.

A comparison of national health care systems suggests different ways to integrate psychosomatic medicine in medical education and clinical practice. Accordingly, in several health care systems the term 'psychosomatic medicine' is used with a different meaning. As in many other countries, in Austria it is primarily interpreted as a comprehensive field with relevance to most if not all medical specialties. Thus, 20 years ago, a continuing medical education programme called 'Psy-Curricula' has been established. This long-term programme can be attended by physicians who have graduated at a medical university and work either as resident physicians or fully licensed physicians. Tuition fees have to be paid for all parts of these courses. The Psy-Curricula are geared towards doctors of all medical fields to facilitate integration of psychosomatic medicine into several areas, e.g. primary care, psychiatry, internal medicine and gynaecology. However, there is no medical specialty or subspecialty in psychosomatic medicine in Austria. The Psy-Curricula consist of three consecutive levels: 'psychosocial, psychosomatic and psychotherapeutic medicine' (table 1).

Graduation at each level is documented by a diploma. Training for level 1 (Psy-1, Diploma for Psychosocial Medicine) takes approximately 1 year $(180 \mathrm{~h})$. At this level, training focuses on medical history taking based on the biopsychosocial model and on improving communication strategies. Furthermore, it informs physicians about treatment options in the psychosocial field [4]. After an additional 2 years $(480 \mathrm{~h})$, trainees can complete level 2 (Psy-2, Diploma for Psychosomatic Medicine). Training at this level qualifies doctors for psychosomatic care including the diagnosis of complex biopsychosocial interaction and integrative approaches to treatment. At level 3 (Psy-3, Diploma for Psychotherapeutic Medicine), after a further 3 years of training $(1,870 \mathrm{~h})$, full psychotherapeutic competence is achieved. Supervision, Balint group training and participation in self-awareness groups are integrative parts of these Psy-Curricula.

A continuously growing number of medical doctors has already completed one or more levels of this programme and has been certified by the Austrian Medical Association. Among all 39,123 medical doctors in Austria in 2009, 2,101 medical doctors have obtained the Psy-1 diploma, 1,669 have reached the Psy-2 level and 1,232 have been certified with a Psy-3 diploma. About $10 \%$ of all Austrian general practitioners who work in private practice have successfully attended at least one of these courses [4]. About half of all physicians who have graduated with a Psy-3 diploma are psychiatrists. Thus, general practice and psychiatry contribute to this programme with the largest groups of participants.

In 1 of 6 training centres for the Psy-Curricula two evaluation studies focused on the effects of this programme [5,6]. Results of one of these studies, based on 30 study participants, suggested a significant increase in patient-centred communication of medical doctors before they had started Psy-1 and after completion of Psy2 [5]. Another study investigated the effectiveness of therapeutic interventions of 35 medical doctors at level Psy-3 with 135 patients and demonstrated significant clinical improvement with regard to different aspects of psychosocial burden as measured by SCL90R, IIP-C, ADS-L and STAI-G after treatment, and even more so half a year later [6]. A third research project aimed to explore

\section{KARGER}

Fax +4161306 1234 E-Mail karger@karger.ch www.karger.com
(C) 2012 S. Karger AG, Basel

0033-3190/12/0816-0391\$38.00/0

Accessible online at: www.karger.com/pps
PD Christian Fazekas, MD

Auenbruggerplatz 2/8

AT-8036 Graz (Austria)

Tel. +4331638583045

E-Mail christian.fazekas@medunigraz.at 
Table 1. Contents of the Psy-Curricula levels 1-3

$\begin{array}{ll}\begin{array}{l}\text { Diploma for 'Psychosocial Medicine' (Psy-1) } \\ 40 \text { units }\end{array} & \text { Biopsychosocial concept of illness } \\ \text { theory } & \text { Doctor-patient relationship } \\ & \text { Basics of doctor-patient communication and } \\ \text { consultation } & \\ \text { Biographic case history } & \text { Psychosocial health care facilities } \\ & \text { Legal basics } \\ & \text { Basics in public health/social issues in medicine }\end{array}$

40 units Balint/supervision group and training of doctor-patient communication

100 units practice in the context of medical work with patients

Overall 180 units - Psy-1

Diploma for 'Psychosomatic Medicine' (Psy-2)

80 units Basics in psychosomatic medicine

theory Basics in mental health (affective disturbances/

disorders, memory, illness behaviour and conflict resolution, personality, compliance)

Diagnosis and treatment of psychosomatic

disorders in children, youths, adults and the

elderly

Life span development and crises

Basics of medical psychotherapeutic methods

Basics of psychopharmacological therapy

Crisis intervention and crisis care in the

doctor's office

Basics of interdisciplinary cooperation

Basics in sexual medicine and gender-specific aspects in psychosomatic medicine

200 units Personal therapy in a continuous group, min.

personal $\quad 80$ units

therapy and Learning one relaxation technique (e.g.

teaching of Jacobson, autogenic training) min. 20 units;

practical continuous Balint group work min. 40 units

psychosomatic Supervision/group work in psychosomatic

skills work, min. 40 units

200 units medical work with patients under psychosomatic aspects

Overall 480 units - Psy-2

the reported clinical routine of general practitioners based on their structured training background in psychosomatic medicine (no Psy diploma, Psy-1, Psy-2, Psy-3) [4]. This questionnaire survey was conducted among a representative national sample of general practitioners and a full sample of general practitioners with one or more Psy diplomas. It focused on the way general practitioners routinely deal with patients who present somatic symptoms which these general practitioners presume to be decisively modulated by psychosocial factors. Respondents without additional training in psychosomatic medicine estimated that an overall $20-30 \%$ of patients in their practice needed psychosomat-

\author{
Diploma for 'Psychotherapeutic Medicine' (Psy-3) \\ 300 units General theory, min. 45 units \\ theory Study of literature, 25 units \\ Specific methods of psychotherapeutic traditions \\ (main schools of psychotherapy: psychoanalytic/ \\ psychodynamic, cognitive behavioural therapy, \\ systemic, humanistic tradition) \\ Major tradition (theory and practical \\ implementation), 150 units: \\ - Introduction, theory and practice in the \\ respective psychotherapeutic method \\ - Diagnostic techniques \\ - Therapeutic short-term methods \\ - Therapeutic long-term methods \\ - Disorder-specific therapeutic approaches \\ - Therapeutic practice in different settings \\ (single, pair, group and family therapy, \\ outpatient and/or inpatient care) \\ Basics of medical psychotherapeutic methods \\ Basics of psychopharmacological therapy
}

150 units personal therapy and teaching of practical psychotherapeutic skills in the major tradition, which has to be continuous over $1-2$ years with a min. of 50 units in single therapy

600 units medical work under psychotherapeutic aspects, with a min. of 50 units in a psychiatric department

100 units supervision and/or Balint group work in relation to medical and psychotherapeutic work

600 units practice in psychotherapeutic medicine in the major tradition

120 units supervision for the psychotherapeutic practice (at least 30 units in single supervision)

Overall 1,870 units - Psy-3 ic care, compared with 30-40\% estimated by general practitioners with such training. The results of this study suggested that some diagnostic approaches, for example clarification of lay aetiology, increased linearly with the level of training.

Currently, a structured integration of psychosomatic medicine in the health care system as a subspecialty for several medical fields is being prepared and discussed. This subspecialty will require Psy- 3 and 3 years of additional clinical training.

A synopsis of the described facts regarding the Austrian approach to psychosomatic medicine suggests a central role of postgraduate training in this field. This approach implies that post- 
graduate programmes addressing the 'biopsychosocial factor' should be open to all medical specialties to overcome the 'dangerous' parts [1] which represent hindrances to a psychosomatic renewal in health care.

\section{Acknowledgements}

No funds were received for this contribution. In the past three years C. Fazekas, MD, has received research support from the Department of Science and Health of the Province of Styria. During the same period of time, A. Leitner, MD, has received support from the Health and Social Fund of the Province of Lower Austria (NÖGUS), from the Lower Austrian Holding Company of Public Hospitals and from the Lower Austrian Health Insurance Company (NÖ GKK).

\section{Disclosure Statement}

The authors declare that there is no conflict of interest.

\section{References}

1 Fava GA, Ruini C, Tomba E, Wise TN: The biopsychosocial factor. Psychother Psychosom 2012;81:1-4.

2 Engel GL: The need for a new medical model: a challenge for biomedicine. Science 1977;196:129-136

3 Tinetti ME, Fried T: The end of the disease era. Am J Med 2004;116: 179-185.

-4 Fazekas C, Matzer F, Greimel ER, Moser G, Stelzig M, Langewitz W, Loewe B, Pieringer W, Jandl-Jager E: Psychosomatic medicine in primary care: influence of training. Wien Klin Wochenschr 2009;12:446453.

5 Langewitz WA, Edlhaimb HP, Höfner C, Koschier A, Nübling M, Leitner A: Evaluation of a two year curriculum in psychosocial and psychosomatic medicine - handling emotions and communicating in a patient centred manner. Psychother Psychosom Med 2010;60:451-456.

6 Edlhaimb HP, Söllner W: Effektivitätsstudie für psychotherapeutische Medizin Psy-3 2002-2007; in Adler RH, Herzog W, Joraschky P, Köhle K, Langwitz W, Söllner W, Wesiack W (eds): Uexküll. Psychosomatische Medizin. Theoretische Modelle und klinische Praxis. München, Urban \& Fischer, 2010, pp 1245-1247. 